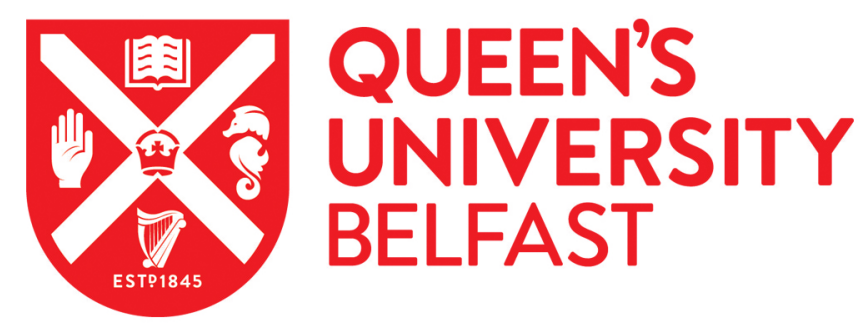

\title{
Shame, Dissociation, and Complex PTSD Symptoms in Traumatized Psychiatric and Control Groups: Direct and Indirect Associations With Relationship Distress
}

Dorahy, M., Corry, M., Black, R. S. A., Matheson, L., Coles, H., Curran, D., Seager, L., Middleton, W., \& Dyer, K. (2016). Shame, Dissociation, and Complex PTSD Symptoms in Traumatized Psychiatric and Control Groups: Direct and Indirect Associations With Relationship Distress. Journal of Clinical Psychology, 72(7). https://doi.org/10.1002/jclp.22339

Published in:

Journal of Clinical Psychology

Document Version:

Peer reviewed version

Queen's University Belfast - Research Portal:

Link to publication record in Queen's University Belfast Research Portal

\section{Publisher rights}

Copyright 2016 Wiley Periodicals, Inc.

This is the peer reviewed version of this following article, which has been published in final form at DOI:10.1002/jclp.22339. This article may be used for non-commercial purposes in accordance with Wiley Terms and Conditions for Self-Archiving.

\section{General rights}

Copyright for the publications made accessible via the Queen's University Belfast Research Portal is retained by the author(s) and / or other copyright owners and it is a condition of accessing these publications that users recognise and abide by the legal requirements associated with these rights.

Take down policy

The Research Portal is Queen's institutional repository that provides access to Queen's research output. Every effort has been made to ensure that content in the Research Portal does not infringe any person's rights, or applicable UK laws. If you discover content in the

Research Portal that you believe breaches copyright or violates any law, please contact openaccess@qub.ac.uk. 
Shame, dissociation and complex PTSD symptoms in traumatized psychiatric and control groups: Direct and indirect associations with relationship distress

Martin J. Dorahy ${ }^{1,2}$, Mary Corry ${ }^{3}$, Rebecca Black ${ }^{4}$, Laura Matheson ${ }^{5}$, Holly Coles ${ }^{5}$, David Curran $^{5}$, Lenaire Seager ${ }^{2}$, Warwick Middleton ${ }^{2} \&$ Kevin F. W. Dyer ${ }^{5,6}$,

${ }^{1}$ Department of Psychology, University of Canterbury, Christchurch, New Zealand

${ }^{2}$ The Cannan Institute, Belmont Private Hospital, Brisbane, Australia

${ }^{3}$ Trauma Resource Centre, Everton Complex, Belfast HSC Trust, Northern Ireland

${ }^{4}$ SET Connects, South Eastern HSC Trust, Northern Ireland

${ }^{5}$ School of Psychology, Queen’s University Belfast, Northern Ireland

${ }^{6}$ Psychological Therapies Service, Northern HSC Trust, Northern Ireland

Running head: SHAME \& DISSOCIATION IN RELATIONSHIP DISTRESS

Word count: 6977

Address correspondence to:

Martin J. Dorahy, Department of Psychology, University of Canterbury, Christchurch, New Zealand. Tel: +64 3364 3416, Fax: +64 3364 2181; Email:

martin.dorahy@canterbury.ac.nz.

Kevin F. W. Dyer, School of Psychology, DClinPsych, David Keir Building, 18-30

Malone Road, Belfast, BT9 5NP, Northern Ireland. Tel: 02890 975632, Fax: 02890

975486; Email: k.dyer@qub.ac.uk. 


\begin{abstract}
Objectives: Elevated shame and dissociation are common in dissociative identity disorder (DID) and chronic posttraumatic stress disorder (PTSD), and also are part of the constellation of symptoms defined as complex PTSD. Previous work examined the relationship between shame, dissociation and complex PTSD, and whether they are associated with relationship anxiety, depression and fear. This study investigated these variables in traumatized clinical samples and a non-clinical community group. Method: Participants were drawn from the DID $(n=20)$, conflict-related chronic PTSD ( $\mathrm{n}=65)$ and non-clinical $(\mathrm{n}=125)$ populations and completed questionnaires assessing the variables of interest. A model examining the direct impact of shame and dissociation on relationship functioning, and their indirect impact via complex PTSD symptoms, was tested through path analysis.

Results: The DID sample reported significantly higher dissociation, shame, complex PTSD symptom severity, relationship anxiety, relationship depression and fear of relationships than the other two samples. Support was found for the proposed model, with shame directly affecting relationship anxiety and fear of relationships, and pathological dissociation directly affecting relationship anxiety and relationship depression. The indirect effect of shame and dissociation via complex PTSD symptom severity was evident on all relationship variables.

Conclusion: Shame and pathological dissociation are not only important for the impact they have on the development of other complex PTSD symptoms, but also their direct and indirect impact on distress associated with relationships.
\end{abstract}

Keywords: Shame, dissociation, complex PTSD, relationship distress 
Shame and dissociation in traumatized psychiatric and control groups: Direct and indirect associations with complex PTSD symptoms and relationship distress

Exposure to chronic traumatic stress, especially of an interpersonal nature, is associated with the development of dissociative and complex posttraumatic stress symptoms, relationship problems and shame (Dutra, Callahan, Forman, Mendelsohn, \& Herman, 2008; Elklit, Hyland, \& Shevlin, 2014). Studies have begun to empirically address these variables in samples with dissociative identity disorder (DID) and posttraumatic stress disorders (PTSD; e.g., Aakvaag, Thoresen, Wentzel-Larsen, Røysamb \& Dyb, 2014; DePrince, Chu, \& Pineda, 2011; Heffernan \& Cloitre, 2000). The primary goal of this study was to extend previous work by statistically evaluating a model that examined the relationship between dissociation, shame, complex posttraumatic stress symptoms, and intimate relationship anxiety, depression and fear. First however, the study sought to determine if previous findings comparing these variables in DID and child-abuse related chronic PTSD could be replicated in a chronic PTSD sample associated with civil conflict. A community control group from the same geographic location as the chronic PTSD sample was used for further comparison.

Dorahy et al. (2015) found no difference in shame, complex PTSD symptoms and relationship distress in DID and chronic PTSD. The etiological stressor for the chronic PTSD sample was child abuse and neglect in all cases. This raises the question of whether similar findings would be evident in a larger sample with chronic PTSD whose etiological stressor was some other interpersonal trauma (i.e., civil conflict) beyond child 
abuse and neglect. This work also called into focus the nature of the association between shame, dissociation, complex trauma symptoms and relationship distress.

Shame, dissociation and dysregulation in relationships are symptom domains and experiences captured by the complex PTSD construct (Herman, 1992; Pelcovitz et al., 1997). Work continues to determine how shame, dissociation and other complex PTSD symptoms (e.g., dysregulation of affect, relationships with others and somatic experience; Dyer, Dorahy, Shannon, \& Corry, 2013) fit together in the adaptation of chronic and relational trauma. It has been proposed that dissociation and shame following exposure to trauma, especially of a repetitive and interpersonal nature, might actually provide a foundation for trauma disorders like PTSD, complex PTSD and DID. For example, Herman (2011) argues that because shame is intrinsic to social subordination, it underpins trauma disorders associated with interpersonal violence, such as PTSD, and Kluft (2007) has noted the significance of shame in DID development. Similarly, Wilson, Droždek, and Turkovic (2006) highlight that following interpersonal violence shame can “stimulate the incubation of PTSD” (p. 127). Andrews, Brewin, Rose and Kirk (2000) found that after controlling a host of demographic variables as well as anger and initial PTSD symptoms, shame in the first 3 weeks following an assault predicted PTSD six months later.

Regarding dissociation, several theorists have argued that it provides a basis for trauma-related disorders (e.g., Dell, 2009). Van der Hart, Nijenhuis and Steele’s (2006) structural theory of dissociation posits that dissociation underpins trauma disorders and the symptoms characterizing them. They suggest the severity and structural sophistication of dissociation increases from PTSD through complex PTSD to DID. With 
increased dissociation at a structural level comes more severe dissociative symptoms (and other symptoms underpinned by dissociation). Research has routinely found higher level of dissociative symptoms in DID compared to other trauma disorders (though c.f., Dorahy et al., 2015), and higher dissociation in complex PTSD compared to PTSD (Dorahy et al., 2013; Putnam et al., 1996). Consequently, it could be argued that dissociation at a structural level underpins trauma disorders and that higher level of dissociative symptoms might be associated with more complex PTSD symptoms.

While shame and dissociation are proffered as key antecedents to other complex trauma symptoms, all three constructs have been associated with distress in interpersonal relationships in traumatized individuals (Dorahy et al., 2013, 2015; Lyons-Ruth, 2003). Typically such distress is conceived primarily as a consequence of shame, dissociation and other complex PTSD symptoms (e.g., Dorahy et al., 2013; Mollon, 2006; Wilson et al., 2006). Drawing together the theoretical and developing empirical literatures, pathological dissociation and shame may underpin other complex PTSD symptoms and produce more relationship distress, but complex PTSD symptoms may mediate the relationship between shame, dissociation and relationship distress.

To assess this formulation, a model was developed that had shame and pathological dissociation as foundational to other complex PTSD symptoms. Shame and pathological dissociation were argued to have direct links to relationship distress in the form of relationship anxiety, relationship depression and fear of intimate relationships, but these connections were also proposed to be mediated (indirectly) by complex PTSD symptoms. Because of the consistent empirical association between shame and dissociation in traumatized groups, and the argument that they may influence each other 
(Dutra et al., 2008; Talbot, Talbot \& Tu, 2004), these variables were correlated in the model. Path analysis was utilized as it provides a viable technique for assessing the appropriateness of a single well-informed theoretical model (e.g., Kalpinski et al., 2013). It extents beyond regression by not only examining the direct effects between variables, but also the indirect effects. In this study the indirect effects were first assessed, and then the direct paths were added.

As well as examining the difference between chronic PTSD, DID and non-clinical controls on dissociation, shame, complex PTSD symptoms and relationship anxiety, depression and fear, this study assessed the direct and indirect effects of dissociation and shame on complex PTSD symptoms and relationship functioning. It was expected that those with DID would have higher levels of shame, dissociation, complex PTSD symptoms and relationship dysfunction than those with chronic PTSD, who in turn would be more symptomatic than controls. Unlike Dorahy et al. (2015), where the DID and the chronic PTSD samples both had child abuse and neglect as their etiological stressor, the chronic PTSD in the current study had conflict-related trauma as their etiological stressor (i.e., the political conflict in Northern Ireland). Regarding the second aim, it was expected that pathological dissociation and shame would have a direct effect of relationship dysfunction, beyond their indirect effects through complex PTSD.

\section{Method}

\section{Participants}

Participants were collected from different settings to reflect 3 distinct groups. The ‘chronic PTSD’ sample was made up of 65 outpatients with chronic PTSD attending a statutory service in Belfast, Northern Ireland dedicated to the psychosocial treatment of 
conflict-related traumatic stress. This sample has been described in detail elsewhere (Dorahy et al., 2013). The 'DID’ sample contained 20 participants with a clinician and structured clinical interview (Dissociative Disorder Interview Schedule; Ross et al., 1989) diagnosis of dissociative identity disorder (DID) attending treatment at a dissociative disorders program in Brisbane, Australia. The 'control' sample was 125 healthy volunteers from Northern Ireland recruited by community posters and university online advertising in Belfast. Due to a processing error the age of participants in the control sample was not collected, but they aged between 18 and 50 years old. The mean age for the chronic PTSD group and the DID group was $40.43(S D=12.42)$ and $45.60(S D=$ 9.41 ), respectively, which did not differ statistically, $F(1,83)=2.93, p=.09$. The chronic PTSD sample was made up of 44 males (68\%) and 21 females (32\%), while the control sample had 24 males (19\%) and 101 females (81\%). All participants in the DID sample were female, as is not uncommon in DID research.

\section{Procedure and Materials}

Participants in the chronic PTSD and DID groups were assessed in a structured clinical interview format after responding to a study invite provided by their treating clinician. Those in the control group responded to an advertisement and again completed the items with the researcher in structured interview format. Following demographic details, participants were administered in random order the Dissociative Experiences Scale (DES; Carlson and Putnam, 1993), The Personal Feelings Questionnaire-2 (PFQ-2; Harder \& Lewis, 1987), the Stress Reactions Checklist for Disorders of Extreme Stress (SRC; Ford, Hawke, Alessi, Ledgerwood \& Petry, 2007), and selected subscales from the Multi-dimensional Relationship Questionnaire (MRQ; Snell, Schicke \& Arbeiter, 1996). 
The DES contains 28 self-report items tapping both pathological and nonpathological types of dissociation (Waller, Putnam \& Carlson, 1996). Respondents address questions on an 11-point scale from $0 \%$ (never) to $100 \%$ (always) regarding their frequency of experiencing each item when not using alcohol or drugs. To isolate pathological dissociative symptoms, mean scores for the eight-item Dissociative Experiences Scale-Taxon (DES-T) were calculated. These eight items on the DES (items $3,5,7,8,12,13,22,27)$ provide a good indicator of pathological dissociative symptoms (Waller et al., 1996). Clinical levels of dissociation are often thought to be indicated by a DES mean of $\geq 30$ (Ross, Norton \& Anderson, 1988). The psychometric properties of the DES have been well supported (see Van IJzendoorn \& Schuengel, 1996).

The PFQ-2 is a 22-item scale of shame and guilt proneness. In this study the ten item trait shame subscale was used. Item ratings are on a 5 point scale from 0 (never experience the feeling) to 4 (experience the feeling continuously or almost continuously). Higher scores signify more shame and guilt. The PFQ-2 has shown good psychometric properties (e.g., Harder and Lewis, 1987). In a mixed psychiatric sample including people with a diagnosis of depression, psychosis, substance abuse, anxiety disorders and borderline personality disorder, Averill, Diefenbach, Stanley, Breckenridge and Lusby (2002) found a mean score for the shame subscale of 18.66. This figure was used as cutoff to determine how many people in each sample scored above this score.

The SRC is a 17-item scale assessing complex PTSD symptoms. Items are responded on a 0 (none of the time) to 4 (all of the time) point scale, with total scores ranging from 0 to 68. Higher scores denote greater complex PTSD symptoms. Ford (personal communication $12^{\text {th }}$ February, 2016) suggests that in studies using community 
groups a score $\geq 20$ is deemed to signify “'High”, or clinical levels of Complex PTSD. The SRC has shown good initial psychometric properties (Ford et al., 2007).

To assess disruptive attitudes and behaviors about emotionally intimate relationships, the Relationship Anxiety, Relationship Depression, and Fear of Relationships subscales from the MRQ were used (Snell et al., 1996). Relationship Anxiety reflects nervousness and discomfort in intimate relationships. Relationship Depression measures negative feelings in intimate relationships. Fear of Relationships assesses fear of engaging in an intimate relationship (Snell et al., 1996). Five items made up each subscale and each item was rated from 0 (not at all characteristic of me) to 4 (very characteristic of me). Higher scores indicated a higher tendency toward each measured variable. These subscales have shown good psychometric properties, including in clinical groups (e.g., Dorahy et al., 2015).

\section{Analysis}

Multivariate Analysis of Variance (MANOVA) was used to examine differences across groups for shame, pathological dissociation, complex PTSD symptoms and relationship functioning. To examine the direct and indirect effects for shame, dissociation and complex trauma symptoms on relationship distress, path analysis using Amos 19.0 software with a maximum likelihood estimator was utilized. Model fit was determined using the recommended fit indices of Chi-square, root-mean squared error of approximation (RMSEA), the comparative fit index (CFI), and the Tucker-Lewis index (TLI). Desirable model fit is indicated when chi-square is non-significant, RMSEA is less than .06, and CFI and TLI statistics are greater than .95 (Hu \& Bentler, 1999). The first model assessed examined the indirect effects of shame and pathological dissociation on 
the relationship outcomes to determine the mediating effect of complex PTSD symptoms. Direct effects were then added systematically to produce the most parsimonious model.

Results

The internal consistency for all questionnaire measures was satisfactory for the entire sample (Table 1). With reference to potential complex PTSD diagnoses for each group, all but one DID participant scored over the cut-off of 19 (95\%). Forty eight (73.8\%) of 65 participants in the chronic PTSD sample scored over this cut-off, while 36 (28.8\%) of 125 controls were over this mark. In terms of clinical dissociation, 16 (80\%) of the 20 DID participants scored 30 or above on the DES. Twenty seven (42\%) of 65 chronic PTSD participants scored above this cut-off, while 34 (27\%) of 125 control participants were above this mark. Regarding the frequency in each sample scoring above 18.66 on the PFQ-2 shame subscale, 18 (90\%) of the 20 DID participants were over this mark, while 35 (54\%) of the 65 chronic PTSD and 42 (34\%) of the 125 control participants were above this cut-off. Table 1 shows the means and standard deviations for each scale across the 3 groups.

Data from each scale for each group was submitted to MANOVA. An overall multivariate effect was found, $\mathrm{V}=.61, F(12,406)=14.86, p<.001, \eta_{\mathrm{p}}{ }^{2}=.31$. Univariate analyses showed group differences on pathological dissociation (DES-T), $F(2,207)=$ 49.76, $p<.001$, shame, $F(2,207)=19.55, p<.001$, complex PTSD symptoms, $F(2,207)$ $=38.04, p<.001$, relationship anxiety, $F(2,207)=36.84, p<.001$, relationship depression, $F(2,207)=66.36, p<.001$ and fear of relationships, $F(2,207)=30.89, p$ $<.001$. Using the Games-Howell post-hoc test due to differences in sample size and homogeneity of variance violations, the DID sample had significantly higher scores on all 
measures than the chronic PTSD sample (DES-T, $p=.001$; Shame, $p=.003$; SRC, $p$ $=.034$; Relationship anxiety, $p=.005$; Relationship depression, $p=.026$; Fear of relationships, $p=.001$ ) and the control sample (DES-T, $p<.001$; Shame, $p<.001$; SRC, $p<.001$; Relationship anxiety, $p<.001$; Relationship depression, $p<.001$; Fear of relationships, $p<.001$ ). In turn the chronic PTSD sample had higher scores on all measures than the control group (DES-T, $p<.001$; Shame, $p=.013$; SRC, $p<.001$; Relationship anxiety, $p<.001$; Relationship depression, $p<.001$; Fear of relationships, $p$ $<.001)$.

Insert Table 1 about here

Regarding the assessment of direct and indirect effects, the complex PTSD measure (i.e., SRC) contained 3 items that assessed dissociation. The correlation between the SRC scale with these items and the SRC scale without them was very high $(r=.98)$. In addition, the correlations between the SRC measure and dissociation remained similar when assessed with (e.g., SRC \& DES-T, r = .67) and without (e.g., SRC \& DES-T, r $=.63$ ) the dissociation items. Thus, to preserve the integrity of the SRC, a decision was made to use the full scale in the path analyses.

The fit indices for model 1a (indirect path via complex PTSD symptoms) were not an adequate overall fit, $\chi^{2}=15.15, d f=6 ; p=.02$; RMSEA $=.09,90 \% \mathrm{CI}=.03-.14$; $\mathrm{CFI}=.99$; $\mathrm{TLI}=.97$, but the standardized regression coefficients for each path were highly significant, suggesting complex PTSD symptoms were relevant to the overall 
model. Model $1 \mathrm{~b}$ added to model $1 \mathrm{a}$ the direct paths from shame to the relationship variables (e.g., anxiety, depression, fear of relationships). Again the fit indices were not adequate, $\chi^{2}=7.10, d f=3, p=.07$; RMSEA $=.08,90 \% \mathrm{CI}=.00-.16$; CFI $=.99$; TLI= .97 , but all paths were significant. Model 1c replaced the direct shame paths with the direct pathological dissociation paths. With the exception of the RMSEA fit indices were adequate, $\chi^{2}=5.81, d f=3, p=.12$; RMSEA $=.07,90 \% \mathrm{CI}=.00-.15$; $\mathrm{CFI}=1$; $\mathrm{TLI}=.98$, but the path between pathological dissociation and fear of relationships was weak and non-significant. Merging the direct and indirect paths, model 1d assessed the full model but with the non-significant path between dissociation and fear of relationships trimmed

(Figure 1). Fit indices were excellent, $\chi^{2}=.43, d f=1, p=.51$; RMSEA $=.00,90 \%$ CI $=.00-.16 ; \mathrm{CFI}=1 ; \mathrm{TLI}=.1$, and all paths were significant except the path between shame and relationship depression. Running the model with this path trimmed produced inferior fit indices (e.g., $\chi^{2}=3.10, \mathrm{df}=2, p=.21$ ) than those of model $1 \mathrm{~d}$, so model $1 \mathrm{~d}$ was accepted as the most parsimonious. The relationship between shame and pathological dissociation was in the moderate range, $r=.53$.

\section{Discussion}

Participants in the study generally reported high levels of trauma symptoms. In the DID group, nearly all participants scores were indicative of high complex PTSD symptoms. Additionally, over three quarters fell above threshold for clinical dissociation as assessed by the DES and 90\% reported very high elevations in shame. For the chronic PTSD sample, 95\% were over the cut-off for high complex PTSD symptoms, just under half fell in the clinical dissociation range and just over half had very elevated shame scores. For the control group, approximately one quarter were above the threshold for 
high complex PTSD symptoms, a quarter were in the clinical dissociation range and a third reported high levels of shame. These heightened levels of distress in the control group may reflect elevated levels of posttraumatic stress and other psychiatric symptoms experienced at a community-level post-conflict in Northern Ireland (Bunting, Ferry, Murphy, O’Neill, \& Bolton, 2013; Muldoon \& Downes, 2007). Despite the chronic PTSD and control groups having quite elevated distress, the DID sample was higher than both groups on shame, complex PTSD symptom severity, pathological dissociation, as well as relationship anxiety, relationship depression and fear of relationships. The chronic PTSD sample produced higher scores on all these measures than the control group. Regarding the assessment of direct and indirect effects, trimming the nonsignificant path between pathological dissociation and fear of relationships produced the most parsimonious fit. Although weak in strength, shame had a direct significant positive association with relationship anxiety and fear of relationships, while pathological dissociation had a direct significant positive association with relationship anxiety and relationship depression. Both shame and pathological dissociation had significant positive indirect effects on all three markers of relationship dysfunction through complex PTSD symptoms. Complex PTSD symptom severity appears to operate as a mediating variable between shame, pathological dissociation and relationship distress. Consequently, as shame and dissociation intensify, complex PTSD symptom severity heightens, which in turn leads to increases in relationship distress. The association between pathological dissociation and fear of relationships was fully meditated through complex PTSD symptoms. The fact that the total effects of shame and pathological dissociation on the relationship variables strengthen considerably in comparison to direct effects, when 
complex PTSD symptom severity was in the model, indicates the importance of this latter construct in understanding the link between shame, pathological dissociation and relationship distress in traumatized individuals.

Consistent with predictions, but in contrast to Dorahy et al.'s (2015) findings, the DID sample in this study had significantly more shame, complex PTSD symptom severity, relationship anxiety, relationship depression, and fear of relationships than the chronic PTSD group. This latter group were made up of participants, who while potentially having a history of child abuse and neglect (Dorahy et al., 2009), had conflictrelated trauma as their primary etiological stressor. The chronic PTSD group used by Dorahy et al. (2015), while smaller, had childhood abuse and neglect as the etiological stressor. Interestingly the raw scores of shame, complex PTSD and relationship distress were slightly lower in the current conflict sample than the abuse sample. However, analyses showed that the groups only differed on fear of relationships and moved towards a significant difference on relationship anxiety, with the maltreatment group having higher scores on both. This is consistent with child abuse and neglect having a particularly corrosive impact on interpersonal relationships (Reyome, 2010).

The dissociative disorder sample used by Dorahy et al. (2015) did not differ on any measure to the DID sample used here. It seems dissociative disorder samples have higher shame, complex PTSD symptom severity and relationship distress than chronic PTSD with conflict-related etiology, but potentially not with childhood maltreatment etiology. Future work is required to test this hypothesis directly using adequate and comparable sample sizes and assessing childhood abuse and neglect in each sample along with the primary etiological trauma in the chronic PTSD groups. 
Consistent with expectations, shame had a direct association with fear of being in an intimate relationship (Mollon, 2006; Kluft, 2007). Cognitive appraisals associated with shame including beliefs of inferiority are likely to heighten fear of engaging in new relationships. Such cognitions and the painful relationship memories that underpin them create concerns about the innumerable ways in which the person may be rejected, exposed or further shamed if they engage in a relationship (e.g., Ferguson, 2005; Gilbert, 1998; Herman, 2011; Lee, Scragg, \& Turner, 2001). Therapy has been shown to have a positive impact on this domain of experience in traumatized individuals (Tummala-Narra, Kallivayalil, Singer \& Andreini, 2012).

In the current investigation, pathological dissociation was related directly to relationship depression. Dorahy et al. (2015) also found an association between these variables, suggesting that ongoing dissociation in daily life including in relationships is likely to erode a person's capacity to feel connected, and heighten a sense of isolation that drives despair in relationships. Both shame and pathological dissociation had a direct effect on relationship anxiety; the feelings of nervousness and discomfort in relationships. The sense of social subordination in shame and the difficulty feeling emotionally present in dissociation may make maintaining relationships particularly anxiety provoking. The link between pathological dissociation and relationship distress in the form of anxiety and depression is in need of further theoretical and empirical work.

Developments from the attachment literature show that dissociative symptoms can stem from particular characteristics within the earlier caregiver-infant relationship, especially regarding lack of maternal responsiveness, flattened affect and disrupted communication (see Dutra, Bianchi, Siegel, \& Lyons-Ruth, 2009). However, it is 
uncertain to what degree this relational-developmental pathway plays a role in producing the link between dissociation and relationship distress in adult life. In those exposed to a relational-developmental context that produces dissociation, relationships in adulthood may remain anxiety-provoking and a cause of despair because the person continues to have their attachment needs ignored or overridden (Dutra et al., 2009). This implies that it may not be dissociation itself that leads to relationship dysfunction in adulthood, but rather previous experiences of disruptive and disorienting relationships. The question is then raised regarding whether dissociation itself produces relationship distress, by perhaps eroding both the capacity for emotional connection and the ability to remain present during moments of intimacy, as mentioned above. It is also uncertain if the same dissociation-relationship dysfunction link is evident in those not faced with a dissociative-producing early interpersonal environment, but rather experience elevated dissociation from interpersonal trauma starting in later childhood, in adolescence or in adulthood.

While shame and pathological dissociation appear to have a direct effect on at least some aspects of interpersonal relationships, the current study indicated that their impact also runs indirectly through complex PTSD symptoms. The theoretical framework proposed has shame and pathological dissociation as antecedents and potentially foundational variables for an array of symptoms that make up the complex PTSD construct (Herman, 2011; Van der Hart at al., 2006). These symptoms, in turn, appear to heighten anxiety and depression in existing relationships and elevate fear in developing new relationships. Complex PTSD symptom severity has been found to predict relationship dysfunction (Dorahy et al., 2013), and the current findings suggest this link 
may be underpinned by shame and pathological dissociation. Clinically, effective efforts to reduce shame and pathological dissociation are likely to have a positive therapeutic impact on relationship dysfunction associated with anxiety, depression and fear, via a direct pathway, or indirectly via reducing complex PTSD symptoms.

The correlation between shame and dissociation was consistent with previous research (Dorahy, 2010, study 1; Talbot, Talbot, \& Tu, 2004). Additionally the strength of the relationship was similar to most research which routinely finds correlations between $r=.3-.55$ (Dorahy et al., 2013; Irwin, 1998, Thomson \& Jaque, 2013).

Interpretation of data needs to be considered in light of study limitations. The DID sample were comparatively small and gender differences existed between groups, which may impact on findings, given shame for example tends to be higher in women (ElseQuest, Higgins, Allison \& Morton, 2012). Given this study was cross-sectional but drew hypotheses based on antecedent and outcome relationships, further work should ideally take a longitudinal approach to assess more adequately the proposed causal associations.

In conclusion, the DID sample in this study were much more shame-prone, dissociative and traumatized than the conflict-related chronic PTSD sample and the nonpsychiatric control group, and reported heightened levels of relationship anxiety, relationship depression and fear of relationships. Shame and pathological dissociation had a direct effect on markers of relationship distress. In addition, shame and pathological dissociation also had an indirect effect on relationship distress via the influence of complex PTSD symptoms. From the current findings, shame and pathological dissociation are not only important for the impact they have on the development of other complex PTSD symptoms, but also their direct and indirect impact 
on distress associated with relationships. Future treatment research examining the sequelae of chronic trauma should target the impact of shame and dissociation on other complex PTSD symptoms and relationship dysfunction. 


\section{References}

Aakvaag, H. F., Thoresen, S., Wentzel-Larsen, T., Røysamb, E., \& Dyb, G. (2014). Shame and guilt in the aftermath of terror: The Utøya Island study. Journal of Traumatic Stress, 27, 618-621.

Andrews, B., Brewin, C. R., Rose, S., \& Kirk, M. (2000). Predicting PTSD symptoms in victims of violent crime: The role of shame, anger and childhood abuse. Journal of Abnormal Psychology, 109, 69-73.

Averill, P. M., Diefenbach, G. J., Stanley, M. A., Breckenridge, J. K., \& Lusby, B. (2002). Assessment of shame and guilt in a psychiatric sample: a comparison of two measures. Personality and Individual Differences, 32, 1365-1376.

Bunting, B. P., Ferry, F. R., Murphy, S. D., O’Neill, S. M., \& Bolton, D. (2013). Trauma associated with civil conflict and posttraumatic stress disorder: Evidence from the Northern Ireland study of health and stress. Journal of Traumatic Stress, 26, 134141.

Carlson, E. B., \& Putnam, F. W. (1993). An update on the dissociative Experiences Scale. Dissociation, 6, 16-27.

Dell, P. F. (2009). Understanding dissociation. In P.F. Dell \& J.A. O’Neil (Eds.), Dissociation and the dissociative disorders: DSM-V and beyond (pp. 709-825). New York: Routledge.

DePrince, A. P., Chu, A., \& Pineda, A. S. (2011). Links between specific posttrauma appraisals and three forms of trauma-related distress. Psychological Trauma: Theory, Research, Practice and Policy, 3, 430-441.

Dorahy, M. J. (2010). The Impact of Dissociation, Shame, and Guilt on Interpersonal 
Relationships in Chronically Traumatized Individuals: A Pilot Study. Journal of Traumatic Stress, 23, 653-656.

Dorahy, M. J., Corry, M., Shannon, M., MacSherry, A., Hamilton, G., McRobert, G., Elder, R. \& Hanna, D. (2009). Complex PTSD, interpersonal trauma and relational consequences: Findings from a treatment-receiving Northern Irish sample. Journal of Affective Disorders, 112,_71-80.

Dorahy, M. J., Corry, M., Shannon, M., Webb, K., McDermott, B., Ryan, M., \& Dyer, K. F. W. (2013). Complex trauma and intimate relationships: The impact of shame, guilt and dissociation. Journal of Affective Disorders, 147, 72-79.

Dorahy, M. J., Middleton, W., Seager, L., McGurrin, P., Williams, M., \& Chambers, R. (2015). Dissociation, shame, complex PTSD, child maltreatment and intimate relationship self-concept in dissociative disorder, chronic PTSD and mixed psychiatric groups. Journal of Affective Disorders, 172, 195-203.

Dutra, L., Bianchi, I., Siegel, D. J., \& Lyons-Ruth, K. (2009). The relational context dissociative phenomena. In P.F. Dell \& J.A. O’Neil (Eds.), Dissociation and the dissociative disorders: DSM-V and beyond (pp. 83-92). New York: Routledge.

Dutra, L., Callahan, K., Forman, E., Mendelsohn, M., \& Herman, J. (2008). Core schema and suicidality in a chronically traumatized population. Journal of Nervous and Mental Disease, 196, 71-74.

Dyer, K. F. W., Dorahy, M. J., Shannon, M., \& Corry, M. (2013). Trauma 
typology as a risk factor for aggression and self-harm in a complex PTSD population: The mediating role of alterations in self-perception. Journal of Trauma and Dissociation, 14(1), 56-68.

Elklit, A., Hyland, P., Shevlin, M. (2014). Evidence of symptom profiles consistent with posttraumatic stress disorder and complex posttraumatic stress disorder in different trauma samples. European Journal of Psychotraumatology, 5, May 19, ArtID: 24221.

Else-Quest, N. M., Higgins, A., Allison, C., \& Morton, L. (2012). Gender differences in self-conscious emotional experience: A meta-analysis. Psychological Bulletin, 138, 947-981.

Ferguson, T. J. (2005). Mapping shame and its functions in relationships. Child Maltreatment, 10, 377-386.

Ford, J. D., Hawke, J., Alessi, S., Ledgerwood, D., \& Petry, N. (2007). Psychological trauma and PTSD symptoms as predictors of substance dependence treatment outcome. Behaviour Research and Therapy, 45, 2417-2431.

Gilbert, P. (1998). What is shame? Some core issues and controversies. In P. Gilbert, \& B. Andrews (Eds.), Shame: Interpersonal behaviour, psychopathology, and culture (pp. 3-38). Oxford: Oxford University Press.

Harder, D. W., \& Lewis, S. J., (1987). The assessment of shame and guilt. In C. Spielberger \& J. N. Butcher (Eds.), Advances in personality assessment, Volume 6 (pp. 89-114). Lawrence Erlbaum, Hillsdale, NJ.

Herman, J. L. (1992). Complex PTSD: A syndrome in survivors of prolonged and repeated trauma. Journal of Traumatic Stress, 3, 377-391. 
Herman, J. L. (2011). PTSD as a shame disorder, in Dearing, R. L., \& Tangney, J. P. (Eds.), Shame in the therapy hour (pp. 261-275). American Psychological Association, Washington, DC.

Heffernan, K., \& Cloitre, M. (2000). A comparison of posttraumatic stress disorder with and without borderline personality disorder among women with a history of childhood sexual abuse: Etiological and clinical characteristics. Journal of Nervous and Mental Disease, 188, 589-595.

Hu, L. \& Bentler, P. M. (1999) Cutoff criteria for fit indexes in covariance structure analysis: Conventional criteria versus new alternatives. Structural Equation Modeling, 6, 1-55.

Irwin, H. J. (1998). Affective predictors of dissociation-II: Shame and Guilt. Journal of Clinical Psychology, 54, 237-245.

Kalpinski, R. J., Williamson, M. L. C., Elliott, T. R., Berry, J. W., Underhill, A. T., \& Fine, P. R. (2013). Modeling the Prospective Relationships of Impairment, Injury Severity, and Participation to Quality of Life Following Traumatic Brain Injury. BioMed Research International, Article ID 102570, http://dx.doi.org/10.1155/2013/102570

Kluft, R P (2007). Applications of innate affect theory to the understanding and treatment of dissociative identity disorder. In E. Vermetten, M. J. Dorahy \& D. Spiegel (Eds.), Traumatic Dissociation: Neurobiology and treatment (pp. 301316). American Psychiatric Press, Inc, Arlington, VA.

Lee, D. A., Scragg, P., \& Turner, S. (2001). The role of shame and guilt in traumatic 
events: A clinical model of shame-based and guilt-based PTSD. British Journal of Medical Psychology, 74, 451-466.

Lyons-Ruth, K. (2003). Dissociation and the parent-infant dialogue: A longitudinal perspective from attachment research. Journal of the American Psychoanalytic Association, 51, 883-911.

Mollon, P. (2006). Shame and jealousy: The hidden turmoils. Karnac, London.

Muldoon, O. T., \& Downes, C. (2007). Social identification and post-traumatic stress symptoms in post-conflict Northern Ireland. British Journal of Psychiatry, 191, $146-149$

Pelcovitz, D., Van der Kolk, B. A., Roth, S., Mandel, F., Kaplan, S., \& Resick, P. (1997). Development of a criteria set and a structured interview for disorders of extreme stress (SIDES). Journal of Traumatic Stress, 10, 3-16.

Putnam, F. W., Carlson, E. B., Ross, C. A., Anderson, G., Clark, P., Torem, M.,...Braun, B. G. (1996). Patterns of dissociation in clinical and nonclinical samples. Journal of Nervous and Mental Disease, 184, 673-679.

Reyome, N. D. (2010). Childhood emotional maltreatment and later intimate relationships: Themes from the empirical literature. Journal of Aggression, Maltreatment \& Trauma, 19, 224-242.

Ross, C. A., Heber, S., Norton, G. R., Anderson, D., Anderson, G., Barchet, P. (1989). The Dissociative Disorders Interview Schedule: A structured interview. Dissociation, 2, 169-189.

Ross, C. A., Norton, G. R., \& Anderson, G. (1988). The Dissociative Experiences Scale: A replication study. Dissociation, 1, 21-22. 
Snell, W. E., Schicke, M., \& Arbeiter, T. (1996). The Multidimensional Relationship Questionnaire: Psychological dispositions associated with intimate relations. Unpublished manuscript.

Talbot, J. A., Talbot, N. L., \& Tu, X. (2004). Shame-proneness as a diathesis for dissociation in women with histories of childhood sexual abuse. Journal of Traumatic Stress, 17, 445-448.

Thomson, P., \& Jaque, S. V. (2013). Exposing shame in dancers and athletes: Shame, trauma, and dissociation in a nonclinical population. Journal of Trauma \& Dissociation, 14, 439-454.

Tummala-Narra, P., Kallivayalil, D., Singer, R., \& Andreini, R. (2012). Relational experiences of trauma survivors in treatment: Preliminary findings from a naturalistic study. Psychological Trauma, 4, 640-648.

Van der Hart, O., Nijenhuis, E. R. S., \& Steele, K. (2006). The Haunted Self: Structural Dissociation and the Treatment of Chronic Traumatization. Norton, New York.

Van IJzendoorn, M. H., \& Schuengel, C. (1996). The measurement of dissociation in normal and clinical populations: Meta-analytic validation of the Dissociative Experiences Scale (DES). Clinical Psychology Review, 16, 365-382.

Waller, N. G., Putnam, F. W., \& Carlson, E. B. (1996). Types of dissociation and dissociative types. Psychological Methods, 1, 300-321.

Wilson, J. P., Drozdek, B., \& Turkovic, S. (2006). Posttraumatic shame and guilt. Trauma, Violence \& Abuse, 7, 122-141. 
Table 1: Descriptive statistics for each scale across groups and internal consistencies for total sample.

\begin{tabular}{|c|c|c|c|c|}
\hline Measures & $\begin{array}{l}\text { DID } \\
\mathrm{N}=20 \\
\text { Mean (SD) }\end{array}$ & $\begin{array}{l}\text { Chronic PTSD } \\
\mathrm{N}=65^{2} \\
\text { Mean (SD) }\end{array}$ & $\begin{array}{l}\text { Control } \\
\mathrm{N}=125^{1} \\
\text { Mean (SD) }\end{array}$ & $\begin{array}{l}\text { Total } \\
\mathrm{N}=210 \\
\text { Mean (SD) }\end{array}$ \\
\hline $\begin{array}{l}\text { DES-T }^{1} \\
\alpha=.90\end{array}$ & $\begin{array}{l}51.06 \\
(26.61)\end{array}$ & $23.63(20.27)$ & $\begin{array}{l}11.53 \\
(12.83)\end{array}$ & $\begin{array}{l}19.04 \\
(20.65)\end{array}$ \\
\hline $\begin{array}{l}\text { PFQ-Shame } \\
\alpha=.83\end{array}$ & 26.15 (7.09) & $19.56(7.58)$ & $16.14(6.22)$ & $18.31(7.33)$ \\
\hline $\begin{array}{l}\text { SRC } \\
\alpha=.87\end{array}$ & $33.70(9.44)$ & 27.25 (10.47) & $\begin{array}{l}15.03 \\
(12.34)\end{array}$ & $\begin{array}{l}20.59 \\
(13.45)\end{array}$ \\
\hline $\begin{array}{l}\text { Relationship } \\
\text { anxiety } \\
\alpha=.89\end{array}$ & $14.60(6.66)$ & $8.86(6.26)$ & $4.69(4.40)$ & $6.92(6.11)$ \\
\hline $\begin{array}{l}\text { Relationship } \\
\text { Depression } \\
\alpha=.92\end{array}$ & 13.35 (6.27) & 8.89 (6.68) & 2.34 (3.39) & $5.42(6.28)$ \\
\hline $\begin{array}{l}\text { Fear of } \\
\text { Relationship } \\
\mathbf{s} \\
\alpha=.83\end{array}$ & $16.00(5.89)$ & 10.08 (5.91) & 6.79 (4.59) & 8.69 (5.85) \\
\hline
\end{tabular}

Notes: ${ }^{1} 1$ control participants did not respond to DES/DES-T item 5; ${ }^{2} 1$ Chronic PTSD participants did not respond to SRC item 1. 
Figure 1: Accepted model (model 1d) with standardized path estimates

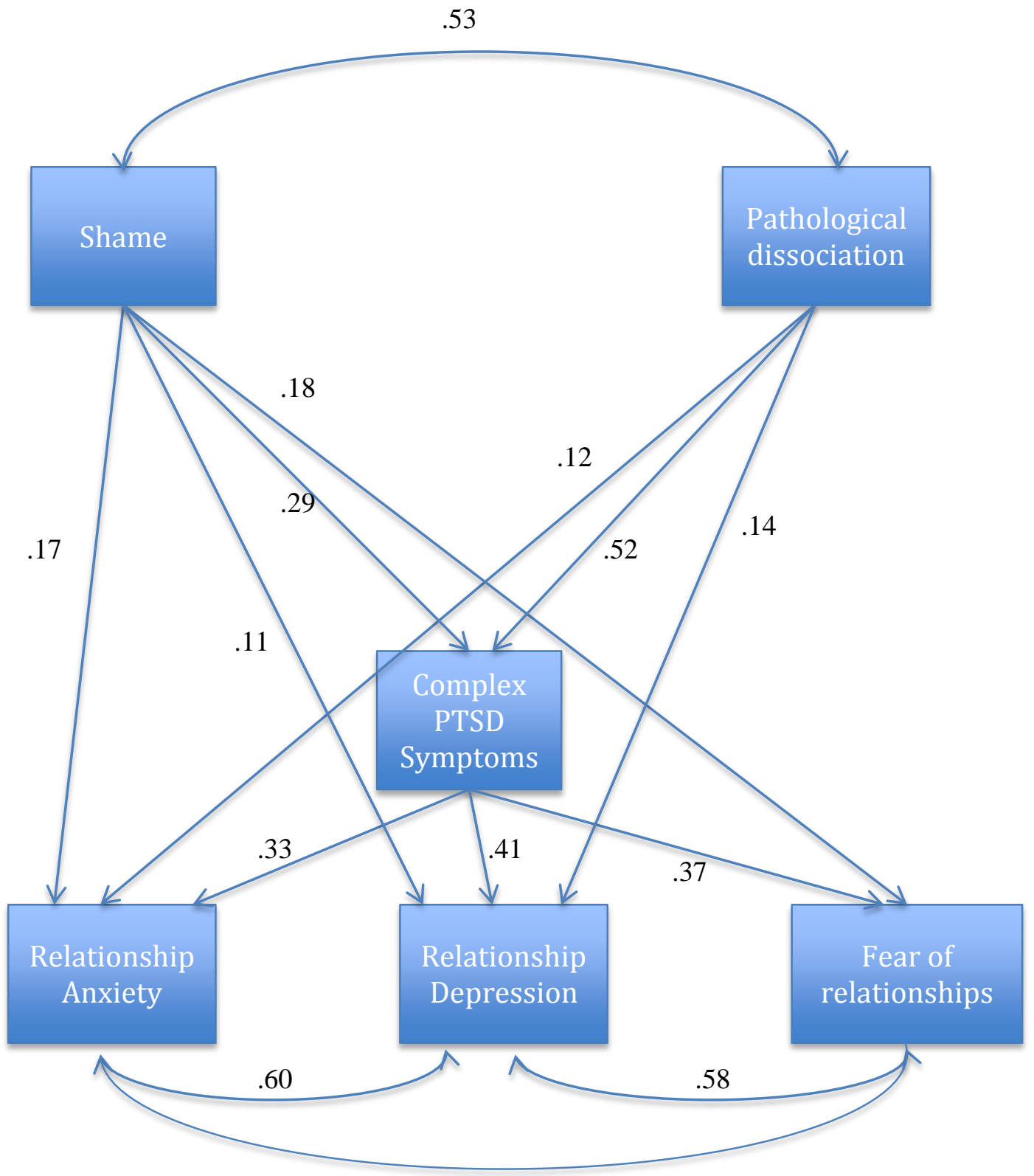

